\title{
Empirical Research on the Impact of Agriculture Technique on Agricultural Output
}

\author{
Peng JIANG ${ }^{1, a}$, Ai-Sheng REN ${ }^{2, b}$ \\ ${ }^{1}$ Institute of Agricultural Information and Economics, Beijing Agriculture and Forestry Academy of Science, Beijing ,China \\ ${ }^{2}$ Institute of Agriculture and Economic Development, Chinese Academy of Agriculture Science, Beijing, China \\ jiangpeng0451@126.com \\ 17125661@qq.com
}

\begin{abstract}
Due to the issues of the current agriculture technique relating to agriculture output, as well as its mutual relationship between both factors, this paper was set up from the interactions among capital input, labor input and technical input of agricultural sectors and modern industrial sectors, agricultural output. Through a production model constructed by agricultural technique and agricultural output, it can be illustrated from the co efficiency regression that agricultural technique progress had a positive relationship with agricultural output. At last, based on the issues reflected from model, some countermeasures were promoted accordingly.
\end{abstract}

\section{Introduction}

A great deal of practice shows that the development of agricultural technology is the first impetus to promote agricultural production. Agricultural technology progress has become the power of agricultural production, and plays an important role in the agriculture production in Agricultural developed countries. In the early 1970 of the 20th century, $60 \%-80 \%$ of the growth in agricultural productivity in the world's major developed countries was achieved by technological progress. In 1929-1972, 81\% of U.S. agricultural growth and $71 \%$ per cent of productivity growth were attributed to agricultural technological advances. From the practice of China's agricultural development, according to the Chinese Academy of Agricultural Sciences, in 1972-1980, 27\% of China's output increment was obtained by agricultural technology progress. In the, agricultural output increased by $35 \%$ and $40 \%$ respectively in the 6th Five-Year Plan and the 7th Five-Year Plan. After more than 20 years of efforts, the contribution rate of agricultural technology development to agricultural growth in China has exceeded $45 \%$.

Since the opening-up policy, China's agricultural production has made considerable progress. In the background of large-scale labor outflow and the shrinking of arable land, the development of agricultural technology provides guarantee for sustained production of agricultural products. February 1, 2012, the CPC Central Committee issued a "state Council to accelerate the promotion of agricultural science and technology innovation to continuously enhance the supply and security of agricultural products in several views", it presents that Agricultural science and technology innovation needs to be accelerated and it plays an important role in the popularization of agricultural technology led by government and the increase of agricultural output. As a large population of developing country, in the case of shortage of arable land resources and insufficient investment in agriculture, speeding up the innovation of agricultural technology is of great significance to guarantee sustainable development of agricultural production. By using time series data to test the influence and size of agricultural technology on China's gross agricultural product since 90, the paper further verifies the importance of agricultural technology to agricultural production.

\section{Research Methods}

\subsection{Assumptions}

According to the method of urban and rural dualistic economy, there are four hypotheses:

1) There are two sectors in the economy: traditional agriculture sector and modern industry sector, the output level of the two departments is determined by the production factors and technical level of each input. The input elements of traditional agriculture sector are capital (mainly land), labor and technology (simple technology), and the input elements of modern industry sector are capital, labor and technology (modern technology).

2) The development of urban economy has reached saturation; the capital supply of modern industry sector and the supply of urban labor are invariable.

3) The scale of the traditional agricultural sector and the modern industry sector pay unchanged. 
4) The labor and capital elements can flow freely between the two sectors and the rural labor force can be transformed into modern industrial labor.

\subsection{The Model of Agricultural Technology's Influence on Agricultural Production}

According to the above assumptions, the C-D production function of the agricultural sector and the modern industry sector can be expressed as follows:

$$
\begin{gathered}
\mathrm{Y}(\mathrm{t})_{1}=F\left[A(t)_{1}, L(\mathrm{t})_{1}, K(t)_{1}\right]=A(t)_{1} L(\mathrm{t})_{1}^{\alpha} K(\mathrm{t})_{1}^{1-\alpha}(0<\alpha<1) \\
\mathrm{Y}(\mathrm{t})_{2}=F\left[A(t)_{2}, L(\mathrm{t})_{2}, K(t)_{2}\right]=A(t)_{2} L(\mathrm{t})_{2}^{\beta} K(\mathrm{t})_{2}^{1-\beta}(0<\beta<1)
\end{gathered}
$$

In Eq.(1), $\mathrm{Y}(\mathrm{t})_{1}$ represents the output of the agricultural sector, $K(t)_{1}$ indicates the amount of capital invested in the agricultural sector, $L(\mathrm{t})_{1}$ is the variable to proxy for the number of labor inputs in the agricultural sector, $A(t)_{1}$ Represents the technical level of the agricultural sector, which reflects the effectiveness of agricultural labor input. In Eq.(2), $\mathrm{Y}(\mathrm{t})_{2}$ represents the number of capital inputs in the modern sector, $K(t)_{2}$ indicates the amount of capital invested in the modern sector, $\mathrm{L}(\mathrm{t})_{2}$ is the variable to proxy for the number of labor inputs in the modern sector, $A(t)_{2}$ indicates the technical level of modern industry in urban area, which reflects the effectiveness of modern industrial labor input. In Eq.(1) and Eq.(2), $\alpha$ and $\beta$ are the labor output elasticity of two sectors respectively. The profit function of the agricultural sector can be expressed as:

$$
\mathrm{r}_{1}=T R_{1}-C_{1}=\mathrm{A}(t)_{1} \mathrm{P}(t)_{1} L(\mathrm{t})_{1}^{\alpha} K(\mathrm{t})_{1}^{1-\alpha} \quad W(t)_{1} L(\mathrm{t})_{1} \quad Z(\mathrm{t})_{1} K(\mathrm{t})_{1}
$$

In Eq.(3), $\mathrm{r}_{1}$ is the profit of agricultural production, $T R_{1}$ is the total income of agricultural production, $C_{1}$ is the total cost of agricultural production, $P(t)_{1}$ is the price of selling agriculture, since agriculture belongs to the necessities of life, its price is controlled strictly by the state, the change range is small, we assume it is unchanged. $W(t)_{1}$ is the wages in agricultural production, $Z(\mathrm{t})_{1}$ is the rental of capital in agricultural production. The labor, capital and the rents of capital are respectively calculated first-order bias and made equal to zero in Eq.(3).Based on profit maximization, and we can get wages engaged in agricultural production and rents for agricultural productive capital:

$$
\begin{gathered}
W(t)_{1}=\alpha \mathrm{A}(t)_{1} \mathrm{P}(t)_{1} L(\mathrm{t})_{1}^{\alpha-1} \mathrm{~K}(\mathrm{t})_{1}^{1-\alpha} \\
Z(\mathrm{t})_{1}=(1-\alpha) \mathrm{A}(t)_{1} \mathrm{P}(t)_{1} L(\mathrm{t})_{1}^{\alpha} \mathrm{K}(\mathrm{t})_{1}^{-\alpha}
\end{gathered}
$$

Eq.(4) by dividing Eq.(5), the following results are obtained:

$$
\mathrm{K}(\mathrm{t})_{1}=\frac{(1-\alpha) \mathrm{W}(t)_{1} L(\mathrm{t})_{1}}{\alpha Z(\mathrm{t})_{1}}
$$

Substituting (6) for (1), the following results are obtained:

$$
\mathrm{L}(\mathrm{t})_{1}=\frac{\mathrm{Y}(t)_{1}}{\mathrm{~A}(t)_{1}}\left[\frac{\alpha \mathrm{Z}(t)_{1}}{(1-\alpha) \mathrm{W}(\mathrm{t})_{1}}\right]^{1-\alpha}
$$

We assume that $\mathrm{TL}(\mathrm{t})_{1}$ is the total agricultural production of labor force, then the number of surplus labor in agriculture $\left(\mathrm{L}(\mathrm{t})_{3}\right)$ can be provided for the modern industrial sector of the rural labor force:

$$
L(\mathrm{t})_{3}=\mathrm{TL}(\mathrm{t})_{1}-L(\mathrm{t})_{1}=\mathrm{TL}(\mathrm{t})_{1}-\frac{\mathrm{Y}(t)_{1}}{\mathrm{~A}(t)_{1}}\left[\frac{\alpha \mathrm{Z}(\mathrm{t})_{1}}{(1-\alpha) \mathrm{W}(\mathrm{t})_{1}}\right]^{1-\alpha}
$$

Similarly, the profit function of the modern industry sector can be expressed as:

$$
r_{2}=T R_{2}-C_{2}=\mathrm{A}\left(t_{2} \mathrm{P}(t)_{2} L(\mathrm{t})_{2}^{\beta} K(\mathrm{t})_{2}^{1-\beta} \quad W(t)_{2} L(\mathrm{t})_{2} \quad Z(\mathrm{t})_{2} K(\mathrm{t})_{2}(9)\right.
$$

In Eq.(9), $r_{2}$ is the profits for the modern industrial sector, $T R_{2}$ is the total income for the modern industrial sector, $C_{2}$ represents the total cost of the modern industrial sector, $\mathrm{P}(t)_{2}$ is the price of products for the modern industrial sector, $W(t)_{2}$ is the wages for the modern industrial sector, $Z(\mathrm{t})_{2}$ is the rent of capital. Likewise,

$$
\mathrm{L}(\mathrm{t})_{2}=\frac{\mathrm{Y}(t)_{2}}{\mathrm{~A}(t)_{2}}\left[\frac{\beta \mathrm{Z}(t)_{2}}{(1-\beta) \mathrm{W}(\mathrm{t})_{2}}\right]^{1-\beta}
$$

This paper assumes that the total urban labor force is $\mathrm{TL}(\mathrm{t})_{2}$, the modern industrial sector needs rural labor force is $\mathrm{L}(\mathrm{t})_{4}$ :

$$
\mathrm{L}(\mathrm{t})_{4}=\mathrm{L}(\mathrm{t})_{2}-\mathrm{TL}(\mathrm{t})_{2}=\frac{\mathrm{Y}(t)_{2}}{\mathrm{~A}(t)_{2}}\left[\frac{\beta \mathrm{Z}(t)_{2}}{(1-\beta) \mathrm{W}(\mathrm{t})_{2}}\right]^{1-\beta} \quad \mathrm{TL}(\mathrm{t})_{2}
$$

$\mathrm{L}(\mathrm{t})_{3}$ equals $\mathrm{L}(\mathrm{t})_{4}$ when the supply and demand balance is available, according to Eq.(8) and Eq.(11) we can get that:

$$
\mathrm{TL}(\mathrm{t})_{1}-\frac{\mathrm{Y}(t)_{1}}{\mathrm{~A}(t)_{1}}\left[\frac{\alpha \mathrm{Z}(t)_{1}}{(1-\alpha) \mathrm{W}(\mathrm{t})_{1}}\right]^{1-\alpha}=\frac{\mathrm{Y}(t)_{2}}{\mathrm{~A}(t)_{2}}\left[\frac{\beta \mathrm{Z}(t)_{2}}{(1-\beta) \mathrm{W}(\mathrm{t})_{2}}\right]^{1-\beta}-\mathrm{TL}(\mathrm{t})_{2}
$$

For easy analysis, this paper assumes that $\alpha$ equals $\beta$, and according to Eq.(12), we can get the salary in a balanced state:

$$
\mathrm{W}=\left[\frac{\frac{\mathrm{Y}(t)_{1}}{\mathrm{~A}(t)_{1}}\left[\frac{\alpha \mathrm{Z}(t)_{1}}{1-\alpha}\right]^{1-\alpha}+\frac{\mathrm{Y}(t)_{2}}{\mathrm{~A}(t)_{2}}\left[\frac{\alpha \mathrm{Z}(t)_{2}}{1-\alpha}\right]^{1-\alpha}}{\mathrm{TL}(\mathrm{t})_{1}+\mathrm{TL}(\mathrm{t})_{2}}\right]^{\frac{1}{1-\alpha}}
$$


Because $\mathrm{L}(\mathrm{t})_{3}, \mathrm{~L}(\mathrm{t})_{4}$ and $\mathrm{L}_{m}$ are equal in equilibrium state, $\mathrm{L}_{m}$ indicates the number of rural labor outflow, according Eq.(8) and Eq.(11) we can get that:

$$
\mathrm{L}_{m}=\frac{\mathrm{TL}\left(\mathrm{t}_{1} \frac{\mathrm{Y}(t)_{2}}{\mathrm{~A}()_{2}}\left[\frac{\alpha \mathrm{Z}(t)_{2}}{1-\alpha}\right]^{1-\alpha}-\mathrm{TL}(\mathrm{t})_{2} \frac{\mathrm{Y}(t)_{1}}{\mathrm{~A}()_{1}}\left[\frac{\alpha \mathrm{Z}(t)_{1}}{1-\alpha}\right]^{1-\alpha}\right.}{\frac{\mathrm{Y}()_{1}}{\mathrm{~A}\left(t_{1}\right.}\left[\frac{\alpha \mathrm{Z}\left(t_{1}\right)_{1}}{1-\alpha}\right]^{1-\alpha}+\frac{\mathrm{Y}(t)_{2}}{\mathrm{~A}(t)_{2}}\left[\frac{\alpha \mathrm{Z}(t)_{2}}{1-\alpha}\right]^{1-\alpha}}
$$

The relationship between the output of the agricultural sector and the outflow of rural Labor can be derived according to Eq.(14):

$$
\mathrm{Y}(t)_{1}=\frac{\mathrm{Y}(t)_{2} \mathrm{~A}(t)_{1}\left[\frac{\alpha \mathrm{Z}(t)_{2}}{1-\alpha}\right]^{1-\alpha}}{\mathrm{A}(t)_{2}\left[\frac{\alpha \mathrm{Z}(t)_{1}}{1-\alpha}\right]^{1-\alpha}} \times \frac{\mathrm{TL}(\mathrm{t})_{1}-\mathrm{L}_{m}}{\mathrm{~L}_{m}+\mathrm{TL}(\mathrm{t})_{2}}
$$

According to 5 and 4 ,

$$
\mathrm{Y}(t)_{1}=\mathrm{Y}(t)_{2} \frac{\left[\mathrm{A}(t)_{1}\right]^{\alpha}}{\mathrm{A}(t)_{2}}\left\{\frac{\mathrm{Z}(t)_{2}\left[\mathrm{~K}(t)_{1}\right]^{\alpha}}{\mathrm{P}(t)_{1}\left[\mathrm{~L}(t)_{1}\right]^{\alpha}}\right\}^{1-\alpha} \times \frac{\mathrm{TL}(\mathrm{t})_{1}-\mathrm{L}_{m}}{\mathrm{~L}_{m}+\mathrm{TL}(\mathrm{t})_{2}}
$$

According to Eq.(16), the technical level of the Shan agricultural sector is positively correlated with the agricultural production, this means that the higher the level of agricultural technology, the more agricultural production. The same conclusion was reached by Huang Tikun and Rozelle by establishing a model of crop production and supply.[Huang Tikun, Rozelle. China's food economy [m]. Beijing: China Agriculture Press, 1998].Therefore, the innovation of agricultural science and technology will improve the efficiency of agricultural production and increase the output of agricultural products. The reasons are as follows: First, the popularization of advanced agricultural technology can improve the level of agricultural scale, the change of decentralized operation, small-scale management, reduce the number of abandoned, to improve the productivity of agricultural land and labor efficiency; Second, the popularization of information technology helps farmers to obtain product and price information in time, expand the sales and service radius of agricultural products and agricultural commodities, Facilitate the Organization and scale of agricultural trade which is decentralized, small and single, promote the transformation of agricultural product supply and sale, solve the problems encountered in the process of agricultural products circulation and sales effectively and improve farmers ' enthusiasm for agricultural production; Third, the popularization of advanced agricultural technology is helpful to attract capital to agriculture, strengthen the enthusiasm of foreign capital to agriculture, increase the input of agriculture, and improve the production efficiency of agriculture. The technical level of modern industry sector is negatively correlated with agricultural production, that is, the higher the level of modern industrial sector, the smaller the agricultural production. Possible reasons are as follows:

First, the higher the level of modern industrial sector leads to the higher quality of labor force in modern industrial sectors, and it may cause a large number of rural high quality labor force to flow out, the shortage of high quality labor required for agricultural production, and may reduce agricultural production efficiency, and then lead to lower agricultural production; Second, the improvement of technical level of modern industrial sector will accelerate the development of modern industry in urban areas, and the rapid development of urban areas will increase the demand for rural labor force, under the premise of low agricultural comparative income, it will induce the outflow of rural labor force, and then cause the labor shortage necessary for agricultural production. Third, the improvement of modern industrial sector technology will have an alternative effect on the labor force and reduce the use of labor. And it may inhibit the outflow of rural labor, hinder the large-scale development of agriculture, reduce efficiency of agricultural production, and decline the production of grain.

\section{Variables and Data Description and Regression Equation}

The analysis shows that capital investment, rural labor force, level of agricultural technology and area of cultivated land are the direct and main factors affecting output. Agricultural Science and technology innovation is very important to improve agricultural production efficiency in the condition that the land resources are not changed or even reduced, and the rural labor force outflow. Is the above conclusion in line with China's actual situation? This paper will use the time series agricultural output, input of agricultural labor force, agricultural fixed capital, agricultural technology level, the total area of crop sowing in Statistics Yearbook of China (1990-2012), China Rural Statistical Yearbook (2012) and China Fixed Assets Investment Statistics Yearbook (2012) Related statistic data ( table 1) to verify the conclusions. Since agricultural technology is a broad concept, it is difficult to define its specific content in statistics. Because the level of agricultural mechanization has played a leading or decisive role in other agricultural technologies, and other agricultural technologies will be difficult to be applied in agricultural production without the widespread use of advanced agricultural machinery, and taking into account the availability of data, we take the total power of agricultural machinery instead of agriculture. Therefore, we use the regression equation for empirical testing. The model is as follows:

$A P=C I^{\gamma_{1}} \mathrm{AL}^{\gamma_{2}} \mathrm{AT}^{\gamma_{3}} \mathrm{SA}^{\gamma_{4}}(17)$

This paper takes logarithm of all variables to eliminate the effect of variance between variables.

$\operatorname{Ln}(A P)_{t}=\mathrm{C}+\gamma_{1} \operatorname{Ln}(C I)_{t}+\gamma_{2} \operatorname{Ln}(\mathrm{AL})_{t}+\gamma_{3} \operatorname{Ln}(\mathrm{AT})_{t}+\gamma_{4} \operatorname{Ln}(\mathrm{SA})_{t}+\varepsilon_{\mathrm{it}}(18)$

The investment of agricultural material capital is measured by the stock of fixed capital of agriculture which is calculated with total agricultural capital formation minus fixed assets depreciation. This paper uses the depreciation rate of fixed assets in the agricultural sector as the agricultural economic depreciation rate in the basic fixed assets depreciation rate of the enterprise, and it is $4.24 \%$.In order to eliminate the impact of inflation, the 1990-year-old agricultural fixed asset investment price index should have been used to calculate the actual physical capital stock, but this 
index is difficult to construct because of the lack of agricultural fixed assets Investment Price index data. Price index of agricultural production materials indicates the relative degree of price change trend and degree of agricultural means of production in a certain period. Therefore, this paper uses the National agricultural production material Price index to replace the agricultural fixed asset price index;
The data of agricultural output, agricultural labor input, total power of agricultural machinery and farm sown area are from the annual Rural Statistical Yearbook of China; $\varepsilon_{\text {it }}$ represents other factors those are not to be considered.

\section{Empirical Results and Analysis}

Table 1. Elements of agricultural inputsand output of agricultural inputs from 1990 to 2012

\begin{tabular}{|c|c|c|c|c|c|}
\hline year & $\begin{array}{l}\text { Agricultural } \\
\text { output } \\
\quad \text { ( hundred } \\
\text { million } \\
\text { RMB) }\end{array}$ & $\begin{array}{l}\text { Stock of fixed } \\
\text { capital in } \\
\text { agriculture } \\
\text { ( hundred } \\
\text { million RMB) }\end{array}$ & $\begin{array}{l}\text { Total power of } \\
\text { agricultural } \\
\text { machinery ( hundred } \\
\text { million RMB) }\end{array}$ & $\begin{array}{l}\text { Input of } \\
\text { agricultural labor } \\
\text { force (ten } \\
\text { thousand) }\end{array}$ & $\begin{array}{l}\text { Total area of } \\
\text { agricultural sowing } \\
\text { ( thousand } \\
\text { hectare) }\end{array}$ \\
\hline 1990 & 7662.1 & 2590.3 & 2870.8 & 38914 & 148362 \\
\hline 1991 & 8157.0 & 2805.1 & 2938.9 & 39098 & 149586 \\
\hline 1992 & 9084.7 & 2930.2 & 3030.8 & 38699 & 149007 \\
\hline 1993 & 10995.5 & 3151.9 & 3181.7 & 37680 & 147741 \\
\hline 1994 & 15750.5 & 3317.9 & 3380.3 & 36628 & 148241 \\
\hline 1995 & 20340.9 & 3593.7 & 3611.8 & 35530 & 149879 \\
\hline 1996 & 22353.7 & 3827.9 & 3854.7 & 34820 & 152381 \\
\hline 1997 & 23788.4 & 3980.7 & 4201.6 & 34840 & 153969 \\
\hline 1998 & 24541.9 & 4083.7 & 4520.8 & 35177 & 155706 \\
\hline 1999 & 24519.1 & 4124.3 & 4899.6 & 35768 & 156373 \\
\hline 2000 & 24915.8 & 4146.4 & 5257.4 & 36043 & 156300 \\
\hline 2001 & 26179.6 & 4253.8 & 5517.2 & 36513 & 155708 \\
\hline 2002 & 27390.8 & 4339.4 & 5793 & 36870 & 154636 \\
\hline 2003 & 29691.8 & 4411.6 & 6038.7 & 36546 & 152415 \\
\hline 2004 & 36239.0 & 4636.6 & 6402.8 & 35269 & 153553 \\
\hline 2005 & 39450.9 & 4766.3 & 6839.8 & 33970 & 155488 \\
\hline 2006 & 40810.8 & 4927.7 & 7252.2 & 32561 & 152149 \\
\hline 2007 & 48893.0 & 5107.8 & 7659 & 31444 & 153464 \\
\hline 2008 & 58002.2 & 5239.0 & 8219 & 30654 & 156266 \\
\hline 2009 & 60361.0 & 5404.4 & 8749.6 & 28890 & 158614 \\
\hline 2010 & 69319.8 & 7587.2 & 9278 & 27931 & 160675 \\
\hline 2011 & 81303.9 & 8440.5 & 9734.7 & 26594 & 162283 \\
\hline 2012 & 89453.0 & 8622.2 & 10255.9 & & 160866 \\
\hline
\end{tabular}

NOTE: The data is from the annual "China Statistical Yearbook", "China Rural Statistical Yearbook", "China Fixed Assets Investment Statistics Yearbook."

Table 2. Regression results

\begin{tabular}{lcccccl}
\hline Variables & Coef & Sign of T & R-squared & Adjusted R & F & Pr>F \\
\hline CI & 0.756825 & 1.461030 & 0.960414 & 0.951100 & 103.1121 & $<0.001$ \\
AL & -0.706029 & -0.241293 & & & & \\
AT & 1.001170 & $4.047169 \cdots$ & & & & \\
SA & -0.657432 & -0.241293 & & & & \\
\hline
\end{tabular}

NOTE: The results are calculated by EVIEWS6.0 software. ${ }^{* * *}$ Indicates that the estimated value in the single tail test in the $10 \%, 5 \%$ of the confidence level is significantly non-zero.

As can be seen from table 2 , the linear equations have higher $R$ value and $f$ value, which shows that the regression equation based on the theoretical model is well fitted.

Based on the regression results, we can draw conclusions as follows:

1)Agricultural technology level (AT) has a significant positive impact on agricultural production, $1 \%$ per cent increase in agricultural technology will increase agricultural production by $1.001 \%$,it means that the higher the agricultural technology, the higher the gross agricultural product. And there are two possible causes are as follows: First, since the 1990s, the development of urban non-agricultural industry and the outflow of large numbers of young adults in rural areas lead to shortage of labor force and increasing abandoned of arable land. And romoting agricultural science and technology innovation can effectively counteract this effect and increase the 
output of agricultural production. Second, due to the accelerating progress of urbanization and industrialization, the fluctuation of agricultural sown area is more frequent, and in the case of arable land scarcity, it is necessary to rely on technological innovation to improve the production.

2) The effect of agricultural fixed capital investment (CI) on output is not significant, which shows that the impact of agricultural fixed capital investment on agricultural production is not obvious.

3) The regression coefficient of agricultural labor input (AL) is negative, which means that the increase in the labor force in agricultural production will reduce the output. This shows that in the case of limited arable land, the current total agricultural labor force in rural areas is surplus. To some extent, this problem hinders the transfer of farmland and the scale of operation, it also restrains the agricultural technology progress and popularization and reduces the labor productivity, which indicates that promoting the integration of urban and rural areas, developing non-agricultural industries and transferring agricultural labor force is of great significance to the improvement of agricultural production. And this conclusion is with Chen Yuanji ET (1994) [Chen Giyuan, $\mathrm{Hu}$ Piliang. The three-dimensional economic structure of China and the transfer of agricultural surplus Labor [j]. Economic Studies, 1994 (4)], Wu (2002) [Wu. The transfer of rural surplus labor and the problem of "three agriculture" [J]. Macroeconomic studies, 2002 (6)] are basically consistent. However, the impact on agricultural production is not significant; indicating whether agricultural labor input in the end has a negative impact on agricultural production is not obvious.

4) The regression coefficients of agricultural sown area (SA) are negative. However, the impact on agricultural production is not significant, indicating that the impact of agricultural acreage on agricultural production is not very obvious, which means that increasing or reducing agricultural acreage, does not necessarily lead to a rise or fall in the total value of agricultural products. As the same time, it is difficult to determine the increasing agricultural acreage to increase agricultural output in the case of a shortage of arable land per capita in China, and to reduce agricultural acreage in the context of the continuous development of agricultural technology will not necessarily reduce agricultural output.

\section{Research Conclusions}

According to the above results, the level of agricultural science and technology has a positive effect on agricultural production, which means that the higher the level of agricultural production, the corresponding increase in the total value of agricultural products.With the progress of urbanization, the rapid development of non-agricultural industry and large rural labor force has transferred into the urban non-agricultural sector with higher wage rate. At the same time, agricultural science and technology innovation hedge the negative impact of rural labor force, and ensure the safety of agricultural production. Secondly, the influence of agricultural fixed capital investment on agricultural production is insignificant. Thirdly, there is a negative correlation between agricultural labor input and agricultural output, and the increase of agricultural labor force will lead to the decrease of agricultural output. At present, the agricultural production in China is constrained by the arable land, the agricultural science, technology input and production level , and the increase of scientific and technological input and production level in agriculture has replaced the rural labor force to some extent. The liberated labor force or the surplus labor force in the countryside will hinder the circulation of farmland in rural areas, and it will inhibit the upgrading and localization of agricultural technology and reduce agricultural productivity and reduce agricultural output. Finally, there is no obvious positive correlation between agricultural sown area and agricultural production, and their changes will not have a significant impact on the other variable, regardless of sown area or agricultural output.

\section{Fund Projects}

Beijing Academy of Agriculture and Forestry Special Fund for Scientific and technological innovation capacity (NO.KJCX20150203)

\section{References}

1. [1] Huangyuxiang etc. agricultural mechanization and the transfer of rural labor force $[\mathrm{J}]$. Agricultural mechanization in China, 2005 (2): 7-10.

2. [2] Yu Qingdong, Li Yaixia. Study on agricultural mechanization and the transfer of rural labor force $[\mathrm{J}]$. Agricultural mechanization Research, 2007 (4): 198-201.

3. [3] Mao Fei, Kong Xiangzhi. General situation and future orientation of China's agricultural modernization [J]. Reform, 2012 (10): 9-21.

4. [4]Koppel and Hawkins.Rural Transformation and the Future of Work in Rural Asia Economic Development and Cultural Change, 1991,42(4),788-805.

5. [5] Shongjiang, Zhang. On the loss and prevention of rural excellent labor force in the process of urbanization [J]. Journal of Jinan Socialist College, 2001 (4): 87-90.

6. [6] Fan Decheng, Wang Zhihua. A study on the role of agricultural scale management in promoting urbanization from the perspective of rural labor force transfer [j]. Economic restructuring, 2011 (6): 81-84.

7. [7] Kiang Minglun etc. Stage characteristics, development trend and countermeasures of agricultural rural development in China $[\mathrm{J}]$. Economist, 2012 (9): 81-90.

8. [8] Yang Minli, White Park. Analysis of the relationship between total power and influencing factors of agricultural machinery [J]. Agricultural Mechanization Research, 2004 (6): 45-47.

9. [9]Hayami Yujiro,God Yoshihisa .Agricultural Economics [M]. China Agriculture Press, 2003 